\title{
El discurso filosófico sobre el terror: Habermas y Derrida
}

\author{
ROY BRAND \\ Instituto de Investigaciones Filosóficas \\ Universidad Nacional Autónoma de México \\ brandroy@gmail.com
}

\begin{abstract}
Resumen: Siguiendo el renovado interés filosófico por el terror y el terrorismo, el presente artículo evalúa la legitimidad y la historia del compromiso filosófico con el terror. El texto ofrece un breve recuento histórico, en el que se relaciona el terror con el dogmatismo y el fanatismo, y luego examina el tratamiento filosófico contemporáneo del concepto de terror en la obra reciente de Habermas y Derrida. En la conclusión abordo las cuestiones de la representación del terror en los medios de comunicación, sus posibles distorsiones y la tarea de la crítica hoy.
\end{abstract}

Palabras clave: comunicación, crítica, dogmatismo, medios de comunicación

\begin{abstract}
Following the renewed philosophical interest in terror and terrorism, this article evaluates the legitimacy and history of the philosophical engagement with terror. It provides a brief historical sketch, relating terror to dogmatism and fanaticism, and examines the contemporary philosophical treatment of the concept of terror in the recent work of Habermas and Derrida. The concluding section addresses the representation of terror in the media, its possible distortions, and the task of criticism today.

Key words: communication, criticism, dogmatism, media
\end{abstract}

En años recientes, tras el horrible ataque terrorista del 11 de septiembre de 2001 y la subsecuente declaración de "guerra contra el terrorismo", un número cada vez mayor de intelectuales y académicos hizo suyo el proyecto de reflexionar sobre la violencia, el terror y las posibilidades de contrarrestar estas amenazas en un marco democrático. Una simple búsqueda en internet arroja como resultado más de una treintena de títulos publicados sólo en el último año sobre el problema del terror y el terrorismo desde varios puntos de vista: filosófico, religioso, psicoanalítico, cultural, ético y político. En este "llamado a las armas" académico se expresa de verdad un sentido de urgencia; sin embargo, la legitimidad del tratamiento académico del problema del terror dista de ser evidente. En este artículo me concentro en la perspectiva filosófica; en particular en la legitimidad y la historia del compromiso filosófico con el terror. ${ }^{1}$

\footnotetext{
${ }^{1}$ Este texto guarda relación con un libro de cuya edición y traducción al hebreo me encargué hace unos meses: Giovanna Borradori, Philosophy in a Time of Terror: Dialogues with Habermas and Derrida. Quiero agradecer a la autora primero por haberme propuesto como traductor de la edición en hebreo, y luego por las múltiples conversaciones que sostuvimos durante mi estancia como profesor visitante en Vassar College y posteriormente. Desde luego, este artículo también toma en cuenta discusiones más recientes que he sostenido con colegas investigadores, especialistas y miembros de los medios de comunicación, acerca de la relevancia de la filosofía y del intelectual público. Tuve la oportunidad de presentar en público
} 
El texto se divide en tres secciones: en la primera parte ofrezco dos breves esbozos históricos, siguiendo a Sócrates y a Wittgenstein, con el fin de mostrar que la filosofía siempre ha tenido que ver con el problema del terror, entendido éste como una forma de dogmatismo o fanatismo. La segunda parte gira en torno a dos de los pensadores contemporáneos más importantes, Jürgen Habermas y Jacques Derrida, y a su análisis del terror como una falla o corte en la comunicación. La tercera parte aborda el problema del dogmatismo (sección 1), el cual, unido al análisis comunicativo del terror (sección 2), nos conduce a la representación del terror en los medios de comunicación, sus posibles distorsiones y la tarea de la crítica hoy día, asuntos de los que me ocupo en la última sección.

\section{Dos esbozos históricos}

Buena parte del debate relacionado con el terror o el terrorismo gira en torno a la propia definición del término. El "terror" no es un fenómeno reciente, pero el terrorismo global como el que enfrentamos hoy día plantea nuevas exigencias a los discursos político, jurídico y filosófico. Hay varias cuestiones que no quedan del todo claras, por ejemplo, si el terrorismo global involucra un nuevo modo de acción; cómo ha de distinguirse del crimen o de la "situación de guerra normal"; si el terror es sólo de grupos o individuos sectarios o si también los estados practican el terror. Además, dado nuestro agitado ambiente político, el término está sujeto a usos o abusos de acuerdo con las distintas agendas de los participantes. Siempre es el otro el que desencadena el terror. $Y$ todos los terroristas afirman estar reaccionando a un acto de terror previo. En este texto no me interesa ofrecer una definición de "terror"; mi objetivo es más bien entender los problemas más generales que atañen a sus estructuras y dinámica. Lo que argumentaré aquí es que el ciclo de violencia se entremezcla con un ciclo de pensamiento, y por ello quiero empezar considerando que el terror es, ante todo, una actitud: una forma de dogmatismo que no reconoce la validez de conjuntos de creencias y valores diferentes.

Permítaseme añadir las siguientes aclaraciones en cuanto al uso que hago de términos como "dogmatismo" y "dogma".

versiones previas de este texto y me beneficié enormemente de los inteligentes comentarios de mucha gente del medio académico y también del no académico. En particular, deseo agradecer a Carlos Pereda y a María Herrera del Instituto de Investigaciones Filosóficas de la UNAM, en la ciudad de México, donde llevé a cabo una estancia de investigación en 2004-2005. También quiero dar las gracias a los participantes del Hurford Humanities Center, en Haverford College, del "Democracy Seminar" en Bennington College, y al público de mis presentaciones sobre filosofía y terror en Tel Aviv y Jerusalén. En este ensayo me propuse conservar el estilo de la presentación, porque creo que ayuda a esclarecer problemas complejos y contribuye a mantener un marco de diálogo. 
1. Un dogma en sí mismo no equivale a terror. Puede haber muchos dogmas inocuos conviviendo en paz con otros (por ejemplo, los judíos ortodoxos en Brooklyn, los amish en Pensilvania). Un dogma se puede traducir en acción violenta sólo cuando se sigue fanáticamente. Uso "fanatismo" entonces para indicar el elemento de pasión o de afirmación extática del propio dogma.

2. No es el contenido del dogma lo que importa, sino su modalidad o forma. Quiero alejarme de la cuestión del contenido ideológico del dogma (sea musulmán, judío, cristiano, utópico o anarquista) para concentrarme, más bien, en su estructura y fuerza; esto es lo que entiendo por "dogmatismo". Considero que este "enfoque formalista" es más conveniente, pues la discusión del contenido conduce rápidamente a un callejón sin salida, mientras que la discusión de la forma permite a los participantes tener una base común sobre la cual pueden coexistir las diferencias. El resultado es que el terror no es propio del mundo islámico o no occidental; puede haber diferentes bandos practicando el terror en la medida en que cierran los ojos y los oídos a los otros y traducen su convicción absoluta en acción violenta. El terror nace, por consiguiente, de una convicción inflexible en nuestra forma de vida, que no permite a los otros expresar sus diferencias. En ciertos casos, esta convicción absoluta se convierte en una auténtica pasión (se sigue hasta el fanatismo) y sólo entonces se puede traducir en acciones violentas que aprueban el autosacrificio y la matanza indiscriminada de otros.

\subsection{Sócrates}

Si de verdad el terror es, en primer lugar, un modo de pensamiento dogmático y sólo posteriormente se convierte en una forma de acción, entonces la filosofía, desde sus orígenes en Grecia y hasta el presente, está intrínsecamente relacionada con el terror. Los diálogos socráticos empiezan reaccionando a la afirmación de certeza o conocimiento absoluto expresado por los expertos de la época - los sofistas que afirman saber lo que es el bien; los políticos que afirman saber cómo deberían ser los estados justos; o los artistas que afirman saber de qué se trata la belleza-. A Sócrates no le interesa reemplazar una idea del bien, lo justo y lo bello con otra; más bien, a través del cuestionamiento incesante, pone al descubierto la falta de conocimiento de sus interlocutores. Los diálogos tempranos no conducen a ninguna conclusión más allá de la destrucción de la convicción inicial; terminan en un estado de aporía, esto es, con un enigma, una pregunta sin respuesta, una situación de confusión o vergüenza — por ejemplo, en el Eutifrón, la piedad es deseada y no deseada por los dioses: ambas posturas se justifican a lo largo del diálogo, pero son mutuamente excluyentes-. 
Ésta, desde luego, es una descripción muy parcial. Se puede decir correctamente que los diálogos socráticos ponen de manifiesto las tendencias opuestas, no hacia la apertura, sino hacia la reificación. ${ }^{2}$ La muerte de Sócrates es, después de todo, la primera explicación de una disposición a morir por razones puramente filosóficas. La filosofía, desde sus comienzos en la Grecia antigua, aspiró al ideal de una verdad eterna, y este ideal la distanció de su presente. La tesis platónica, tal como la interpreta la tradición, era que si palabras como "bien", "justicia", "belleza" o "ser humano" tenían algún sentido, entonces éste debe relacionarse con la esencia de las cosas - una esencia inmutable- Éste o aquel "bien" pueden ir y venir, pero la palabra "bien" conserva su significado más allá de la multiplicidad de sus ocurrencias; se trata de una idea eterna. Según este enfoque esencialista, la tarea de la filosofía es aproximarse, todo lo posible, a las esencias eternas y no ocuparse, hasta donde sea posible, de las particularidades históricas concretas.

Sócrates inició la búsqueda filosófica de esencias, pero también opuso resistencia a cualquier pretensión de conocimiento cierto o absoluto, incluido el propio. Por un lado, a través de sus preguntas parece suponer una esfera ideal de las esencias eternas, y, por el otro, niega que podamos tener acceso a él. Los diálogos socráticos son, al mismo tiempo, dogmáticos y escépticos. Es esta combinación que da a la filosofía su nombre -amor al conocimiento- lo que indica que la búsqueda (el amor) del conocimiento (absoluto) es tan importante como su logro, y que los dos, el deseo de conocimiento (absoluto) y el hecho de que éste no se pueda satisfacer por completo, están profundamente entrelazados.

\subsection{Wittgenstein}

Esta tensión, digamos entre dogmatismo y escepticismo, convicción y duda, es una de las maneras de contar la historia de la filosofía, poniendo el énfasis en una trama crítica. Quiero añadir ahora un segundo y breve esbozo histórico; esta vez data de principios del siglo xx. La obra de Wittgenstein, temprana y tardía, puede interpretarse como una incisiva crítica a las pretensiones de conocimiento no sustentadas o al intento mismo de construir nuestras relaciones con el mundo exclusivamente en términos del conocimiento. $(\mathrm{O}$, dicho de manera más específica, en términos de conocimiento representacional, en lugar de, digamos, agencia o sensibilidad estética.)

\footnotetext{
${ }^{2}$ No sigo la distinción aceptada por los especialistas entre periodo temprano, medio y tardío en Platón. En primer lugar, no existe evidencia real de que esta distinción de hecho se sostenga históricamente; se trata meramente de una distinción heurística que ya comporta el interés de la interpretación. En segundo lugar, aun en la llamada etapa temprana, las preguntas de Sócrates indican claramente un impulso hacia la certeza y al mismo tiempo niegan el conocimiento absoluto.
} 
En el Tractatus, la fuerte posición crítica de Wittgenstein en contra de las pretensiones de conocimiento no sustentadas lo conducen a negar la posibilidad de la ética, la estética o, de hecho, de la filosofía en su conjunto, incluida, de manera aporética, la suya propia. La ética y la estética tienen que ver con valores, no con hechos; ellas no remiten a cosas que existen en el mundo ni son exactamente verdaderas o falsas, tal como lo son los enunciados empíricos. Por lo tanto, según el Tractatus, no tienen un sentido determinado y, para ser cautelosos, deberíamos pasarlas por alto en silencio. Como lo expresa la famosa última proposición (7) del Tractatus: "De lo que no se puede hablar, es mejor callar."3

En sus Investigaciones filosóficas, la exigencia de guardar silencio se relaja. Podemos hablar del bien, de lo bello o del mundo en su conjunto, pero debemos ser conscientes de que nuestras palabras están ligadas a nuestras prácticas y que, por lo tanto, siempre son relativas, temporales y finitas. El Wittgenstein de la etapa tardía constantemente lucha contra lo que él denomina "imágenes cautivadoras" de que hay una forma dogmática de pensamiento que dirige nuestra mirada a las esencias eternas, más que a nuestras prácticas cotidianas. Estas imágenes cautivadoras incluyen: la visión lógico-matemática del mundo, la visión empírico-científica, así como la primera distinción wittgensteiniana entre lo que se puede y lo que no se puede decir. Tales imágenes cautivadoras determinan de antemano cómo entendemos e interpretamos la multiplicidad de cosas; imponen dogmáticamente un marco de referencia y evitan las complejidades y las ambigüedades de nuestras "formas de vida". La obra de Wittgenstein (a la que él llamaba su "terapia filosófica") tiene por objeto desbaratar estas configuraciones de pensamiento obsesivo poniendo al descubierto su dinámica. Como en el caso de Sócrates, para Wittgenstein la filosofía no es un cuerpo de doctrina, sino una actividad que lucha por desbaratar nuestros conceptos reificados y nuestras formas fijas de pensar a partir de ellos.

\section{Habermas y Derrida}

Es posible añadir muchos más ejemplos de la lucha de la filosofía en contra de su propio momento de dogmatismo (e.g., el proyecto crítico de Kant y la Genealogía de Nietzsche son otros dos ejemplos importantes al respecto), pero creo que lo que pretendía decir ha quedado claro y por ello prefiero abreviar y pasar al debate contemporáneo.

\footnotetext{
${ }^{3}$ Esta marcada postura positivista debe ser puesta en contexto. A Wittgenstein no le interesa negar la posibilidad del valor o del valor práctico de la filosofía; por el contrario, quiere conservarlo exactamente como valor, es decir, como algo diferente del hecho. Hacer afirmaciones concernientes a "lo bueno" o "lo bello" corre el riesgo de transformar el valor en hecho, esto es, transformar actitudes, juicios y acciones en objetos o esencias.
} 
Lo que espero haber mostrado hasta ahora es que el compromiso filosófico con la amenaza del terror, concebido como una forma de pensamiento que sueña con que sabe de manera absoluta o que conoce lo absoluto, es interno a la filosofía misma. La filosofía reacciona a esta amenaza volviéndose crítica, esto es, tomando conciencia de los límites del conocimiento humano o de los límites del lenguaje. No hay relativismo en tal enfoque. El relativismo no es sino la otra cara de la moneda esencialista, pues plantea la tesis de que "todo es relativo" como una verdad eterna. Más allá de estos dos extremos, la filosofía crítica subraya la experiencia histórica concreta y lo hace sin dar pie al relativismo, es decir, sin abandonar una pretensión de universalidad y acuerdo racional. La racionalidad y la universalidad no son ideas eternas que podamos alcanzar en algún momento; más bien se realizan a través de nuestras prácticas discursivas cuando nuestras afirmaciones se evalúan tomando como base las mejores o peores justificaciones.

Es importante hacer notar que estos dos esbozos de Sócrates y Wittgenstein ponen de relieve una tensión que existe, dentro de la propia filosofía, entre las pretensiones de conocimiento y el deseo de certeza por una parte, y las exigencias de la crítica y la experiencia humana, por la otra. La filosofía goza de una posición privilegiada para combatir nuestro estado actual de dogmatismo (y fanatismo), aunque sólo sea porque su historia ha sido definida por tales encuentros. En nuestros tiempos, contrarresta la amenaza de dogmatismo desarrollando un léxico y métodos para pensar las diferencias dentro de un marco de referencia inclusivo y universal. ${ }^{4}$ Creo que éste es el significado del llamado filosófico al pensamiento crítico hoy día, y Habermas y Derrida son los representantes más destacados de la filosofía crítica de la segunda mitad del siglo xx.

\subsection{Habermas}

La contribución de Habermas consiste en haber desarrollado una "teoría de la acción comunicativa"; es decir, un marco de referencia para explicar la importancia de las prácticas dialógicas como medios para llegar a un acuerdo universal racional. Según Habermas, no recibimos por anticipado

\footnotetext{
${ }^{4}$ Esto entraña imaginación política. Como Paul Gilroy lo explica: "necesitamos saber qué tipos de cosas hay que comprender y sobre cuáles hace falta reflexionar para poder ayudar realmente a sociedades cada vez más diferenciadas y a individuos ansiosos a lidiar exitosamente con los retos que implica vivir tranquilamente cerca de lo no conocido sin volverse temerosos y hostiles" (Postcolonial Melancholia, p. 3). Creo que uno de los principales vehículos de esa imaginación política es el arte; en el arte experimentamos la otredad como fuente de fortaleza, y la apertura como algo revitalizador. El arte, siempre y en especial hoy, explora nuevos modelos de convivencia. Tal cual Nicolas Bourriaud escribe: "Como parte de una teoría 'relacionista' del arte, la intersubjetividad no sólo representa el escenario social para la recepción del arte, que es su 'ambiente', su 'campo' (Bordieu); también se convierte en la quintaesencia de la práctica artística." Véase Relational Aesthetics, p. 22.
} 
la racionalidad y la autonomía como ideas eternas; éstas se realizan a través de la práctica misma de la participación dialógica. Dicho de otra manera, para realizarme como agente racional, necesito un interlocutor y una estructura dialógica. Si carezco de un compañero que escuche y reaccione a mis afirmaciones, o si las condiciones no permiten un diálogo abierto y equitativo, entonces mi propia racionalidad y mi autonomía padecen las consecuencias.

Habermas sitúa el concepto de "acción comunicativa" en la base de su pensamiento y presenta el conflicto político como un corte en la comunicación. El corte en la comunicación es violencia o la violencia estalla precisamente cuando la comunicación dialógica se interrumpe. Tal interrupción entraña riesgos para la racionalidad y la autonomía de ambos bandos, pues aquéllas sólo se pueden desarrollar en un marco de diálogo. La solución que propone Habermas supone desarrollar prácticas sofisticadas de comunicación, promover instituciones internacionales (como la ONU y el Tribunal Internacional de la Haya, mejorando al mismo tiempo su capacidad para poner en práctica sus resoluciones) y fomentar un sentido de cosmopolitismo y cooperación. ${ }^{5}$ (Por ejemplo, Habermas cree que después del ataque terrorista del 11 de septiembre hubo un amplio consenso internacional en cuanto a los riesgos del terror. Él cita, como ejemplo, la cooperación internacional manifestada al rastrear y bloquear cuentas bancarias sospechosas, así como en las deliberaciones concernientes a diferentes posibilidades de establecer un ejército o acción policiaca internacional.)

\subsection{Derrida}

El nombre de Derrida es casi sinónimo del método o la práctica de la deconstrucción. Su motivación básica es dar expresión a las dimensiones o elementos reprimidos, esto es, dar voz a quienes fueron excluidos del marco de referencia hegemónico o dominante. Además, la deconstrucción muestra, una y otra vez, que la mera exclusión del otro es la forma en la cual el marco dominante establece su propia identidad. Dicho de una manera más sencilla, debo distinguirme de lo más cercano a mí a fin de

\footnotetext{
${ }^{5}$ Es importante tener en mente la distinción entre globalismo y cosmopolitismo. El proceso de globalización hace referencia al mercado, al turismo, la información y la técnica. El cosmopolitismo remite a los derechos humanos, a las libertades, la cultura y la democracia. El cosmopolitismo ha sido secuestrado o reducido al globalismo, pues los dos se dirigen al nivel supranacional; pero si bien la globalización es, sobre todo, de índole económica, el cosmopolitismo todavía dirige nuestra atención a las relaciones entre la política y nuestra naturaleza humana compartida, a la idea de "ciudadanía del mundo" y al ideal de que los humanos se unirán como un todo sin allanar sus diferencias. Este ideal incluye un elemento estético central, pues lo que puede unirnos como humanos no será nunca una ideología, sino nuestras formas de sensualidad.
} 
establecer mi identidad independiente. ${ }^{6}$ Esto da como resultado una paradoja, pues el otro es necesario para definir mi identidad, precisamente en su condición de reprimido y excluido.

Tanto Habermas como Derrida subrayan de modos distintos la importancia del diálogo y la participación. Sin el otro no hay yo y nuestra identidad como individuos o como comunidad se constituye sólo en el contexto de la multiplicidad. Con respecto al terrorismo global actual, Derrida piensa que éste es un defecto interno de la modernidad misma: un acto violento cuya intención es suprimir o eliminar al otro que está dentro. Este acto es autodestructivo o incluso suicida, pues ese otro es parte de nosotros mismos. El terror, entonces, expone de una forma violenta los conflictos internos que fueron escondidos o reprimidos por la modernidad en su marcha hacia cierta visión del progreso. Derrida no especifica qué es lo reprimido, pero creo que podemos incluir en ello las dimensiones de la tradición, de la fe, del valor de la familia y de la importancia del territorio. Éstas fueron excluidas o reprimidas con la llegada de la Ilustración, pero son necesarias, en su condición de excluidas, para que la modernidad defina su propio sentido de identidad. ¿Qué es la modernidad si no la exclusión de la tradición y la fe, y el comienzo desde cero (piénsese, por ejemplo, en el primer comienzo de Descartes, la tabula rasa de Locke o la posición original de Rawls; o, alternativamente, en la moda y su obsesión con lo nuevo; la moda -la mode - comparte su nombre con la modernidad)? Como estos elementos quedan excluidos del debate racional, sólo pueden expresarse por la vía de la violencia.

Aquí el problema es también una falla de comunicación. Sólo que, en el caso de Derrida, los interlocutores no son externos, sino internos. Si, para Habermas, el terror es un síntoma de la falta de comunicación entre el mundo occidental, democrático y rico, y el otro mundo, para Derrida el terror indica la creciente marginación del otro en el seno de la propia modernidad. Para tratarlo, por consiguiente, hay que empezar por reconocer estos conflictos y admitir la dinámica de exclusión y represión, así como dar voz y prestar oídos a lo que ha sido silenciado y reprimido. Esta conversación se parece más a una conversación con el inconsciente, que a un diálogo racional entre iguales. Debemos aprender a escuchar las voces que hablan en una lengua distinta; poner atención a los silencios, las interrupciones, las fisuras, los síntomas o las equivocaciones. Derrida, como Habermas, apoya el papel de las instituciones internacionales como propiciadoras de un diálogo, pero también pone de relieve la importancia de un cambio de actitud que acogiera a la otredad no meramente como un

\footnotetext{
${ }^{6}$ En El malestar en la cultura, Freud llama a esto el "narcisismo de las diferencias menores", que describe la agresión y el odio mutuo de los grupos muy cercanos y estrechamente relacionados.
} 
interlocutor externo, sino como una promesa real y como un riesgo real que siempre está ya dentro.

Este importante punto de desacuerdo entre Habermas y Derrida tiene que ver con la posibilidad del diálogo, su forma y la diferencia entre los interlocutores. He elegido subrayar aquí las similitudes y entablar una especie de intercambio entre sus enfoques, pero es importante hacer notar que Habermas y Derrida conciben la falla de comunicación de maneras radicalmente diferentes. Habermas criticaría a Derrida por plantear una forma de conversación que no es del todo racional, mientras que Derrida criticaría a Habermas por permitir sólo un tipo de racionalidad que dicte los términos del debate. Habermas apoya una actitud de "tolerancia", esto es, la aceptación de la otredad en condiciones de respeto mutuo y un compromiso con un procedimiento de acuerdo racional. Derrida apunta a una noción mucho más radical de aceptación, a la que denomina "hospitalidad" y que admite la otredad incondicionalmente y con los riesgos reales.

Es sorprendente descubrir lo adecuado que es el vocabulario filosófico de Habermas y Derrida para una discusión del terrorismo global. A veces parece que su pensamiento progresó de manera consistente hacia un compromiso exactamente con el mismo conjunto de problemas. Podemos contrastar este modelo de compromiso filosófico con un segundo modelo presentado, por ejemplo, por Bertrand Russell y Noam Chomsky. ${ }^{7}$ Tanto Russell como Chomsky lograron fama y prestigio contribuyendo a los campos de la lógica y la lingüística, respectivamente. Ambos usaron su prestigio de manera acertada para expresar importantes inquietudes relacionadas con la carrera nuclear, los derecho humanos, el medio ambiente y la guerra contra el terrorismo. Pero estos dos conjuntos de preocupaciones, las intelectuales y las políticas, son, para ellos, cosas totalmente ajenas. Podríamos incluso pensar que son contradictorios, pues su obra intelectual toma como premisa la suposición de una estructura eterna (la lógica para Russell, y el lenguaje universal para Chomsky), mientras que su trabajo político se conduce en el nivel de las prácticas situadas históricamente.

Habermas y Derrida, por otra parte, presentan una imagen del intelectual público cuyas opiniones políticas y éticas no son secundarias respecto de sus inquietudes filosóficas, sino que surgen directamente a partir de ellas. ${ }^{8}$ Un año de diferencia separa su nacimiento (Habermas nació en Alemania en 1929, y Derrida, judío francés, en Argelia en 1930). Am-

\footnotetext{
${ }^{7}$ Tomo este contraste de la introducción de Giovanna Borradori a Philosophy in a Time of Terror: Dialogues with Habermas and Derrida.

${ }^{8}$ Gramsci establece una distinción diferente, aunque relacionada, entre el "intelectual tradicional" y el "intelectual orgánico". Los primeros están vinculados históricamente a la elite social y económica y se distinguen por su competencia literaria, científica o filosófica profesional. Los segundos, "los intelectuales orgánicos", se distinguen menos por su profesión, que puede ser un trabajo cualquiera característico de su clase, que por su función como guías y organizadores de las ideas y aspiraciones de su clase. Los primeros se conciben como agen-
} 
bos llegaron a la madurez filosófica en el momento en que los horrores del holocausto se volvieron cada vez más evidentes, y ambos desarrollaron métodos filosóficos que podían ofrecer los recursos para abordar los problemas de la modernidad, vistos desde sus respectivas posiciones. Habermas desarrolló un modelo de racionalidad basado en la práctica de un diálogo abierto; y Derrida desarrolló un método que da voz a los otros que han sido excluidos. Por lo tanto, es posible pensar que Habermas y Derrida trabajaron en el mismo proyecto a partir de diferentes fines. Habermas describe el movimiento que va de los conflictos individuales hacia los acuerdos universales; mientras que Derrida se mueve desde lo que se presenta como una verdad universal hacia los conflictos internos que ella entraña. A diferencia del punto de vista común que sitúa a Habermas y a Derrida en mutua oposición (como representantes del pensamiento moderno y posmoderno, respectivamente), esta interpretación de sus proyectos a la luz de sus posiciones comprometidas deja claro que ambos comparten la idea de que la filosofía está vinculada a la historia de una manera que no evita que aspire a la universalidad o incluso a un tipo de eternidad. Según Habermas, la universalidad se realiza a través de las prácticas dialógicas; mientras que para Derrida, se realiza precisamente cuando esta universalidad se expone a su propia multiplicidad interna.

\section{La representación del terror y la tarea de la crítica}

El problema del dogmatismo y el análisis comunicativo del terror nos llevan a considerar el papel de los medios de comunicación en lo que a mitigar o propagar la amenaza del terror se refiere. Si el terror es, ante todo, una forma de pensamiento dogmático, el cual se expresa o se realiza como un modo de comunicación distorsionada o rota, entonces la representación del terror en los medios de comunicación y el discurso al respecto no son meros añadidos a lo que sucede, sino que tienen una participación activa en él — toman parte en el terrorismo y operan de una manera u otra-.

Los medios de comunicación, tal como cualquier otra forma de discurso, no son inmunes a la acusación de dogmatismo. En este caso, como antes, no es el contenido de la representación sino su forma lo que equivale a dogmatismo. Por ejemplo, la repetición de las imágenes del 11 de septiembre por sí misma tiene una manera de imponernos una posición unilateral. Ahora bien, no quiero decir que estén en favor de uno u otro de los contendientes de esta "guerra". Curiosamente, las mismas imágenes pueden servir a la causa del terror o a la causa de la guerra contra el terror -para exponer la vulnerabilidad del objetivo, para ofrecer la cobertura más amplia de la violencia y la amenaza y, con ello, ampliar sus poderes,

tes independientes y autónomos, y los segundos reconocen sus relaciones intrínsecas con las condiciones que intentan transformar. Véase Antonio Gramsci, "The Intellectuals". 
así como justificar un fuerte contraataque-. La unilateralidad no se debe al contenido de las imágenes, sino al hecho de que dogmáticamente hacen sonar los tambores de la guerra y convierten el diálogo en algo aparentemente irrelevante o imposible. La imagen insiste aquí en que es absoluta; su repetición llena el aire y nuestras mentes con una dosis siempre mayor de lo mismo. ${ }^{9}$ En este caso, el dogmatismo se acerca al fanatismo, pues los medios de comunicación tienen el poder retórico de inyectar pasión en la convicción. ${ }^{10}$

En nuestros tiempos, el terror opera en el escenario global echando mano del discurso y las imágenes. Por horrible que suene, no hay nada nuevo sobre el terrorismo, sobre las matanzas indiscriminadas de miles de civiles inocentes desde Hiroshima hasta el Cercano Oriente, pasando por Bosnia y Ruanda. Como Habermas y Derrida lo subrayan, la monstruosidad del 11 de septiembre no se debe al número de víctimas ni a su muerte casi instantánea. Lo que no tiene precedente en este acontecimiento es el poder simbólico de los objetivos. El Pentágono y el World Trade Center son íconos importantes en la reserva de imágenes del mundo, pues representan el orden económico, jurídico y militar del orbe. Este orden no es sólo estadounidense, aunque Estados Unidos funja como su más fuerte defensor; se trata del orden del mundo global en el que vivimos todos -el orden que garantiza el flujo de dinero en los mercados, la seguridad y la estabilidad de los estados soberanos, la legitimidad de las leyes, de hecho, la legitimidad de nuestros propios discursos-. Como aquí se trata de imágenes, la presencia de los medios de comunicación es de importancia crucial. Los medios de comunicación transformaron en un espectáculo mundial lo que potencialmente sólo fue un acontecimiento local. Siguiendo a Habermas y a Derrida, se puede argumentar que el 11 de septiembre es el primer acontecimiento histórico global: el choque, la explosión, el lento derrumbamiento — todo esto ya no es Hollywood, sino una horrible realidad que

\footnotetext{
${ }^{9}$ La repetición también esconde lo incomprensible. No entendemos mejor el suceso viéndolo repetidamente; simplemente nos acostumbramos a él. Ante la incomprensibilidad de aquel suceso (donde Sócrates diría "ignorancia" y Wittgenstein pediría guardar silencio), los medios de comunicación intentan enmendar el trauma por la vía de la histeria.

${ }^{10}$ Debemos tener cuidado de no describir este hecho como un suceso estético. La estetización es evidente en Jean Baudrillard y Karlheinz Stockhausen. El primero al afirmar que "todos, sin excepción, fantaseamos sobre este acontecimiento" (véase J. Baudrillard, L’Esprit du terrorisme), y Stockhausen al valorar el 11 de septiembre como una de las obras de arte más sublimes. Existe un horrible sentido de júbilo en sus comentarios sobre el hecho. Las imágenes de la destrucción del poder podría de verdad inducir a lo sublime (una mezcla de terror y placer, como en los análisis de Kant y Burke), hay en efecto algo fascinante en torno a este horrible espectáculo trágico del sacrificio de individuos. Pero hace falta hacer una crítica de esta falsa idea. (La sección que pone fin a la "Analítica de lo sublime" nos advierte en contra de "la falsa idea de querer ver algo más allá de los límites de la sensibilidad", o de "delirar con la razón"; Immanuel Kant, Crítica de la facultad de juzgar, Ak. 275.) Es necesario que la entendamos sin deleitarnos en ello y sin negar que es efectiva.
} 
ocurrió en la sala de un público global universal-. No hay manera de contar lo que individuos diferentes viviendo en continentes diferentes sintieron cuando los edificios se colapsaron; pero todos vimos las mismas imágenes, y lo más probable es que las hayamos visto simultáneamente.

El terrorismo global adquiere entonces un poder simbólico espectacular, tanto que sin los medios de comunicación no puede haber terrorismo global. Desde luego, no tengo intención aquí de culpar a los medios por los hechos; sólo quiero hacer notar que nuestros modos de representar el terror no pueden ser excluidos de la discusión de lo que el terror es y de cómo opera. Esto es cierto también con respecto al discurso intelectual concerniente al terror y a las discusiones del terror en las esferas públicas. Es nuestro modo de comunicación o representación —no lo que decimos, sino cómo lo decimos- lo que corre el riesgo de caer en el dogmatismo. ¿Cuál es, entonces, la tarea de la crítica?

Dado nuestro involucramiento performativo en la representación del terror, y el hecho de que no existe el observador imparcial ni nada que se le parezca, queda claro que la tarea de la crítica sería analizar no el contenido de nuestras afirmaciones individuales, sino su forma. Podemos llamar a esto:

1. El cambio formal del contenido hacia la fuerza: la tarea de los críticos no es juzgar el contenido de las diferentes afirmaciones, sino la forma en que permiten o restringen un diálogo.

Dadas la importancia de la comunicación, y la estructura dialéctica de la identidad y la otredad, la crítica no debe centrarse en las prácticas individuales, sino en las relacionales. Las relaciones interhumanas no son sólo el escenario para la recepción de la crítica, no son únicamente su campo o ambiente, sino el tema mismo de la crítica. Mientras que en la crítica clásica o en la primera teoría crítica se ponía el énfasis en la emancipación del individuo de la opresión de estructuras de poder más grandes, lo que hace más falta en nuestros días es desatascar la comunicación entre humanos. Podemos llamar a esto:

2. El cambio relacional de lo individual a las relaciones interhumanas: la tarea de la crítica no es liberar al individuo, sino las prácticas de comunicación interhumana, así como promover la producción de nuevos tipos de relaciones entre la gente.

La crítica efectiva atañe actualmente no al dogma, sino al dogmatismo, y no al individuo, sino a las redes comunicativas. La tarea de la crítica es hoy día alejarnos gradualmente del dogmatismo (el cual también es siempre un modo de comunicación o la falta de ésta) para movernos hacia un espacio de diálogo e interrelación no sólo con los otros, sino también con nosotros 
mismos. Esto no supone la erradicación de nuestras pretensiones individuales (no estamos juzgando su contenido); por el contrario, tal práctica no sólo permitirá, sino que de hecho promoverá nuestra libertad y autonomía, pues sólo podemos vernos como singulares cuando nos reflejamos en el espejo de la pluralidad.

Para concluir, el terror reta a la modernidad a que entre en un estado de mayor multiplicidad y cosmopolitismo, a que continúe la búsqueda de universalidad, concebida como prácticas de comunicación más inclusivas y abiertas. Este desafío no es nuevo para la filosofía. La práctica de la filosofía, desde Sócrates hasta Wittgenstein, y desde Habermas hasta Derrida, atañe menos al planteamiento de tesis y argumentos y más a la limitación de nuestras pretensiones de conocimiento y su ubicación en un escenario de diálogo más inclusivo.

En 1946, al concluir su monumental estudio sobre la historia del pensamiento occidental (History of Western Philosophy), Bertrand Russell resumió de manera sucinta el resultado práctico de más de dos mil años de filosofía: "Enseñar cómo vivir sin certeza, y, sin embargo, sin paralizarse por la vacilación, es tal vez lo principal que la filosofía, en nuestra era, puede hacer todavía por aquellos que la estudian."11 Estas palabras, escritas justo después de la Segunda Guerra Mundial en respuesta a la devastación de los regímenes fascistas y totalitarios, todavía hoy resuenan poderosamente.

[Traducción de Laura E. Manríquez]

\section{BIBLIOGRAFÍA}

Baudrillard, Jean, L'Esprit du terrorisme, Éditions Galilée, París, 2001.

Borradori, Giovanna, Philosophy in a Time of Terror: Dialogues with Habermas and Derrida, The University of Chicago Press, Chicago, 2003; edición en hebreo: Hakibbutz Hameuchad, Tel Aviv, 2004. [Versión en castellano: Filosofía en una época de terror: conversaciones con Jürgen Habermas y Jacques Derrida, Taurus, Madrid, 2004.]

Bourriaud, Nicolas, Relational Aesthetics, Les Presses du Réel, Dijon, 2002 (1a. ed. en francés: 1998).

Gilroy, Paul, Postcolonial Melancholia, Columbia University Press, Nueva York, 2004. Gramsci, Antonio, "The Intellectuals", en Selections from the Prison Notebooks, Lawrence and Wishart, Londres, 1971, pp. 3-23. [Versión en castellano: Antología, trad. M. Sacristán, México, 1970.]

Russell, Bertrand, History of Western Philosophy, Routledge, Londres, 1946. [Versión en castellano: Historia de la filosofía occidental, trad. J. Gómez de la Serna y A. Dorta, Espasa-Calpe, Madrid, 1971.]

Recibido el 22 de junio de 2005; aceptado el 29 de septiembre de 2005.

${ }^{11}$ Bertrand Russell, History of Western Philosophy, p. 14. 